\title{
ERECTILE DYSFUNCTION
}

\section{CRISTIAN DELCEA}

\author{
Iuliu Hațieganu University of Medicine and Pharmacy, Cluj-Napoca, Romania \\ Sexology Institute of Romania, Cluj-Napoca, Romania
}

\begin{abstract}
Erectile dysfunctionis is defined as the persistent inability to achieve or maintain an erection sufficient for satisfactory sexual performance. In most sexual intercourses you have a Marked difficulty in obtaining an erection and / or a marked difficulty in maintaining an erection and / or a marked decrease in stiffness. Worldwide prevalence of erectile dysfunction is occasionally $13 \%-21 \%$ for those $40-80$ years old; frequently $2 \%$ for those $40-50$ years old; significantly $40 \%-50 \%$ for those $60-70$ years old; and $8 \%$ for those who have stopped penetrating during the first sexual. The erectile dysfunction may emerge from the beginning of the sexual life or begin after a period of relatively normal sexual function.
\end{abstract}

Keywords: erectile dysfunction, s-on, therapy, testing, evaluation, sexual disorders.

\section{INTRODUCTION}

One can book an appointment online, by phone, sms. You will receive confirmation of the appointment date and you will be asked to pay for the first intervention, after which you will take the necessary steps for the chosen activity. After payment and proof of payment you will go through each step below.

There will be a complex evaluation and testing with the S-ON Test (c) Clinical Sexual Assessment System.

After testing, you will complete the 7 standardized S-ON Sextherapy $₫$ protocols to address sexual and / or couple issues.

The next step is using S-ON Monitoring@ for monitoring and feedback throughout the entire period of interventions to improve erectile dysfunction as well as S-ON Optimization (C) to optimize sexual performance and couple's relationship.

You will receive more details during our interventions.

\section{How do I pay for the service and how much does it cost?}

The payment is made online into the account of Institute of Sexology: bank account: RO45BTRL06701205M34615XX opened at Banca Transilvania. And the cost for each intervention (evaluation, testing, intervention protocol) is 100 euro at the NBR (National Bank of Romania) exchange rate.

\author{
Let's start! \\ Testing, S-ON Test $(C$ \\ Protocols, S-ON Sextherapy $@$ \\ Monitoring, S-ON Monitoring $₫$ \\ Optimizing, S-ON Optimization@
}

\section{APPLICATIONS \\ - Testing, S-ON Test $₫$ MEN Screening-DSM/DE (S-DSM/DE)}

INSTRUCTIONS. You will find below a checklist of 8 questions that describe the actions that men take in various sexual intercourses.

*Corresponding author: 160 Plevnei Street, Cluj-Napoca, 400000, Romania, Phone/Fax: 0264 550247, email cristian.delcea.cj@gmail.com 
For each question, check the option that best suits you.

1/8 You have a market difficulty in getting erections after an adequate stimulation

Not at all

A little

A lot

Very much

Extremely

2/8 You have a weak/ semi-flaccid erection or you are not able to maintain it through 6 or 7 out of 10 sexual intercourses.

Not at all

A little

A lot

Very much

Extremely

3/8 Your erection is not firm/strong during penetration

Not at all

A little

A lot

Very much

Extremely

4/8 It has appeared after a long time, reported to the beginning of sexual life

Not at all

A little

A lot

Very much

Extremely

5/8 Erectile dysfunction occur with your stable long-term partner

Not at all

A little

A lot

Very much

Extremely

6/8 Erectile dysfunction occur irrespective of the partner

Not at all

A little

A lot
Very much

Extremely

7/8 There an anticipatory fear of a new sexual failure

Not at all

A little

A lot

Very much

Extremely

8/8 You have couple issues regarding sexual intercourses

Not at all

A little

A lot

Very much

Extremely

\section{Answers}

- Not at all, 0 percentages.

- A little, 10 percentages, MILD erectile dysfunction is confirmed. This means that you have signs and symptoms of marked difficulty in getting, maintaining erection and a marked decrease in erection rigidity.

- A lot, 20 percentages, MODERATE erectile dysfunction is confirmed. This means that you have signs and symptoms of marked difficulty in getting, maintaining erection and a marked decrease in erection rigidity.

- Very much, 30 percentages, SEVERE erectile dysfunction is confirmed. This means that you have signs and symptoms of marked difficulty in getting, maintaining erection and a marked decrease in erection rigidity.

- Extremely, 40 percentages, EXTREMELY SEVERE erectile dysfunction is confirmed. This means that you have signs and symptoms of marked difficulty in getting, maintaining erection and a marked decrease in erection rigidity.

- Testing, S-ON Test $₫$ MEN

Sexual stimuli genogram SSG-m

INSTRUCTIONS. You will find below a set of 3 questions that describe the actions 
that men do in various sexual acts. For each question, check the option that best suits you. Choose the answer you think is most appropriate. You must tick from 1-10 the intensity of pleasure (sexual attraction), relaxation (sexual disposition) and arousal (sexual stimulation). These ticked grades, in terms of pleasure, relaxation and arousal are the category of stimuli that you work with during the sexual intercourse. You have to think carefully about what you choose to identify your real answer.

1. PLEASURE (the extent to which you feel attracted by stimuli below)

Face

\begin{tabular}{|l|l|l|l|l|l|l|l|l|l|}
\hline 1 & 2 & 3 & 4 & 5 & 6 & 7 & 8 & 9 & 10 \\
\hline
\end{tabular}

Neck

\begin{tabular}{|l|l|l|l|l|l|l|l|l|l|}
\hline 1 & 2 & 3 & 4 & 5 & 6 & 7 & 8 & 9 & 10 \\
\hline
\end{tabular}

Chest

\begin{tabular}{|l|l|l|l|l|l|l|l|l|l|}
\hline 1 & 2 & 3 & 4 & 5 & 6 & 7 & 8 & 9 & 10 \\
\hline
\end{tabular}

Abdomen

\begin{tabular}{|l|l|l|l|l|l|l|l|l|l|}
\hline 1 & 2 & 3 & 4 & 5 & 6 & 7 & 8 & 9 & 10 \\
\hline
\end{tabular}

Arms

\begin{tabular}{|l|l|l|l|l|l|l|l|l|l|}
\hline 1 & 2 & 3 & 4 & 5 & 6 & 7 & 8 & 9 & 10 \\
\hline
\end{tabular}

\section{Penis}

\begin{tabular}{|l|l|l|l|l|l|l|l|l|l|}
\hline 1 & 2 & 3 & 4 & 5 & 6 & 7 & 8 & 9 & 10 \\
\hline
\end{tabular}

\section{Buttocks}

\begin{tabular}{|l|l|l|l|l|l|l|l|l|l|}
\hline 1 & 2 & 3 & 4 & 5 & 6 & 7 & 8 & 9 & 10 \\
\hline
\end{tabular}

\section{Legs}

\begin{tabular}{|l|l|l|l|l|l|l|l|l|l|}
\hline 1 & 2 & 3 & 4 & 5 & 6 & 7 & 8 & 9 & 10 \\
\hline
\end{tabular}

\section{Back}

\begin{tabular}{|l|l|l|l|l|l|l|l|l|l|}
\hline 1 & 2 & 3 & 4 & 5 & 6 & 7 & 8 & 9 & 10 \\
\hline
\end{tabular}

2. RELAXATION (the extent to which you enjoy the stimuli below)

Face

\begin{tabular}{|l|l|l|l|l|l|l|l|l|l|}
\hline 1 & 2 & 3 & 4 & 5 & 6 & 7 & 8 & 9 & 10 \\
\hline
\end{tabular}

Neck

\begin{tabular}{|l|l|l|l|l|l|l|l|l|l|}
\hline 1 & 2 & 3 & 4 & 5 & 6 & 7 & 8 & 9 & 10 \\
\hline
\end{tabular}

\section{Chest}

\begin{tabular}{|l|l|l|l|l|l|l|l|l|l|}
\hline 1 & 2 & 3 & 4 & 5 & 6 & 7 & 8 & 9 & 10 \\
\hline
\end{tabular}

\section{Abdomen}

\begin{tabular}{|l|l|l|l|l|l|l|l|l|l|}
\hline 1 & 2 & 3 & 4 & 5 & 6 & 7 & 8 & 9 & 10 \\
\hline
\end{tabular}

Arms

\begin{tabular}{|l|l|l|l|l|l|l|l|l|l|}
\hline 1 & 2 & 3 & 4 & 5 & 6 & 7 & 8 & 9 & 10 \\
\hline
\end{tabular}

\section{Penis}

\begin{tabular}{|l|l|l|l|l|l|l|l|l|l|}
\hline 1 & 2 & 3 & 4 & 5 & 6 & 7 & 8 & 9 & 10 \\
\hline
\end{tabular}

\section{Buttocks}

\begin{tabular}{|c|c|c|c|c|c|c|c|c|c|}
\hline 1 & 2 & 3 & 4 & 5 & 6 & 7 & 8 & 9 & 10 \\
\hline \multicolumn{10}{|c|}{ Legs } \\
\hline 1 & 2 & 3 & 4 & 5 & 6 & 7 & 8 & 9 & 10 \\
\hline \multicolumn{10}{|c|}{ Back } \\
\hline 1 & 2 & 3 & 4 & 5 & 6 & 7 & 8 & 9 & 10 \\
\hline
\end{tabular}

3 AROUSAL (the extent to which you are stimulated/ aroused by stimuli below)

Face

\begin{tabular}{|c|c|c|c|c|c|c|c|c|c|}
\hline 1 & 2 & 3 & 4 & 5 & 6 & 7 & 8 & 9 & 10 \\
\hline \multicolumn{10}{|c|}{ Neck } \\
\hline 1 & 2 & 3 & 4 & 5 & 6 & 7 & 8 & 9 & 10 \\
\hline
\end{tabular}

\section{Chest}

\begin{tabular}{|l|l|l|l|l|l|l|l|l|l|}
\hline 1 & 2 & 3 & 4 & 5 & 6 & 7 & 8 & 9 & 10 \\
\hline
\end{tabular}

\section{Abdomen}

\begin{tabular}{|l|l|l|l|l|l|l|l|l|l|}
\hline 1 & 2 & 3 & 4 & 5 & 6 & 7 & 8 & 9 & 10 \\
\hline
\end{tabular}

\section{Arms}

\begin{tabular}{|l|l|l|l|l|l|l|l|l|l|}
\hline 1 & 2 & 3 & 4 & 5 & 6 & 7 & 8 & 9 & 10 \\
\hline
\end{tabular}

\section{Penis}

\begin{tabular}{|l|l|l|l|l|l|l|l|l|l|}
\hline 1 & 2 & 3 & 4 & 5 & 6 & 7 & 8 & 9 & 10 \\
\hline
\end{tabular}

\section{Buttocks}

\begin{tabular}{|l|l|l|l|l|l|l|l|l|l|}
\hline 1 & 2 & 3 & 4 & 5 & 6 & 7 & 8 & 9 & 10 \\
\hline
\end{tabular}

\section{Legs}

\begin{tabular}{|l|l|l|l|l|l|l|l|l|l|}
\hline 1 & 2 & 3 & 4 & 5 & 6 & 7 & 8 & 9 & 10 \\
\hline
\end{tabular}

Back

\begin{tabular}{|l|l|l|l|l|l|l|l|l|l|}
\hline 1 & 2 & 3 & 4 & 5 & 6 & 7 & 8 & 9 & 10 \\
\hline
\end{tabular}

\section{Answers}

- 5-7 percentages, Mild: Your cognitive involvement and utilization of excitatory, pleasure and relaxation stimuli is maladaptive. The number of excitatory stimuli is reduced (you are focused only on two or four excitatory stimuli maximum) and your sexual behavior is guided only towards those unrepresentative stimuli, failing control sexual intercourse.

- 3-5 percentages, Moderate: Your cognitive involvement and utilization of excitatory, 
pleasure and relaxation stimuli is maladaptive. The number of excitatory stimuli is very reduced (you are focused only on one or maximum three excitatory stimuli) and your sexual behavior is guided only towards those unrepresentative stimuli, failing control sexual intercourse.

- 1-3 percentages, Severe: Your cognitive involvement and utilization of excitatory, pleasure and relaxation stimuli is maladaptive. The number of excitatory stimuli is extremely reduced (you are focused only on one or maximum two excitatory stimuli) and your sexual behavior is guided only towards those unrepresentative stimuli, failing control sexual intercourse.

\section{- Testing, S-ON Test@ MEN Cognito-sexual questionnaire SCSb}

INSTRUCTIONS. You will find below a checklist of 15 questions that describe the actions of men in various sexual intercourse. For each question, check the option that best suits you.

\section{1/15 What do you THINK of during intercourse} regarding what you hear?

1. Sounds of your partner's hyperventilation (inhalation and exhalation acceleration), the sound of movements and other auditory sensations

2. Your partner verbalizing words with sexual connotations

3. A part of the first two options above

4. You don't give too much importance to auditory sensations

\section{2/15 What do you THINK of during intercourse regarding what you see}

1. Intimate positions that will allow you to see your partner during intercourse and your partner's body

2. Your partner's body

3. A part of the first two options above

4. You don't give too much importance to visual sensations
3/15 What do you THINK of during intercourse regarding what you smell

1. Your partner's body

2. On some parts of your partner's body

3. A part of the first two options above

4. You don't give too much importance to smell and taste sensations

\section{4/15 What do you THINK of during intercourse} regarding what you touch

1. You focus on details when touching your partner (focus on face, neck, breasts, abdomen, vagina, buttocks, legs, back, arms)

2. You focus on overall caresses (you focus only on some parts of your partner's body)

3. A part of the first two options above

4. You don't give too much importance to tactile sensations

\section{5/15 What do you THINK of during intercourse} regarding your moves

1. You practice more positions (classic missionary, man on top, doggy-style, etc.) in a sexual intercourse

2. You practices 1 or maximum two positions (classic missionary, man on top, doggystyle, etc.) in a sexual intercourse

3. Your sexual activity is more dinamic and with few moves

4. You don't give too much importance to your moves during intercourse

6/15 What do you FEEL during intercorse regarding what you hear

1. Hearing sensations that produce wellbeing, pleasure and excitement

2. Hearing sensations that produce excitement and pleasure

3. Hearing sensations that produce pleasure

4. Hearing sensations that don't produce well-being, pleasure and excitement

7/15 What do you FEEL during intercorse regarding what you see

1. Visual sensations that produce well-being, pleasure and excitement

2. Visual sensations that produce excitement and pleasure

3. Visual sensations that produce pleasure 
4. Visual sensations that don't produce wellbeing, pleasure and excitement

8/15 What do you FEEL during intercorse regarding what you touch

1. Tactile sensations that produce well-being, pleasure and excitement

2. Tactile sensations that produce excitement and pleasure

3. Tactile sensations that produce pleasure

4. Tactile sensations that don't produce wellbeing, pleasure and excitement

9/15 What do you FEEL during intercorse regarding what you smell

1. Taste and smell sensations that produce well-being, pleasure and excitement

2. Taste and smell sensations that produce excitement and pleasure

3. Taste and smell sensations that produce pleasure

4. Taste and smell sensations that don't produce well-being, pleasure and excitement

10/15 What do you FEEL during intercorse regarding your moves

1. Motion sensations that produce well-being, pleasure and excitement

2. Motion sensations that produce excitement and pleasure

3. Motion sensations that produce pleasure

4. Motion sensations that don't produce wellbeing, pleasure and excitement

11/15 What do you DO during intercorse regarding what you see

1. You insist on watching your partner and you use your imagination when you can't see parts of the body

2. You prefer positions that will allow you to see your partner during intercourse, to the detriment of those that don't allow you to do this

3. Your eyes are guided only by sensations

4. You don't use too much visual senses during intercourse
12/15 What do you DO during intercorse regarding what you hear

1. You prefer to communicate during sexual intercourse for sexual dinamics

2. You are involved in communication during intercourse

3. You let yourself being driven by erotic words during intercourse

4. You are involved in what you hear

13/15 What do you DO during intercorse regarding what you touch

1. Your touches are made in successive steps (you touch all the body parts even the insignificant ones)

2. Your touches are short and frequent (meaning "more quickly", "in a hurry", "on the run")

3. Your touches are only made on parts of the body with maximum excitement

4. You don't touch too much during intercourse

14/15 What do you DO during intercorse regarding what you smell

1. You insist to smell parts of your partner's body (all parts of the body with erotic significance)

2. Sometimes you can smell parts of your partner's body (some parts of the body with erotic significance)

3. You stimulate olfactory and gustative senses during intercourse

4. You usually do nothing regarding smell

15/15 What do you DO during intercorse regarding your moves

1. Your movements are acurate and consistent (good management of movements during intercourse)

2. Your movements are balanced (a good style of having sex)

3. You have no control over movements (you can't find the "place" and "the right time" to have sex)

4. You are passive during intercourse (you prefer woman in dominant role) 


\section{Answers}

- Mild: Your cognitive-behavioral involvement in excitatory stimuli is maladaptive. Your thinking, sensation and behavioral process is not well-managed/ adaptively used.

- Moderate: Your cognitive-behavioral involvement in excitatory stimuli is maladaptive. Your thinking, sensation and behavioral process is not sufficiently managed/ adaptively used.

- Severe: Your cognitive-behavioral involvement in excitatory stimuli is maladaptive. Your thinking, sensation and behavioral process is insufficient concerning the adaptive management.

\section{- Interventions, S-ON Sextherapy@ Men Protocol of sexual cognitive scenario, $\mathrm{S}-\mathrm{ONde}$ cognitive@ \\ Erectile dysfunction}

\section{General consideration}

The protocol of S-ONde cognitive@ sexual cognitive scenario was scientifically validated with the purpose of helping men to develop a cognitive-behavioural participation by insisting on sexual stimulus, thus reaching and maintaining the erection.

This technique uses cognitive scenarios and several steps to help men rediscover how to be involved at a cognitive-behavioural level by using relevant sexual stimulus of sexual desire.

In fact, it is a self guidance in how to participate at the cognitive-behavioural level only to the excitation stimulus by using descriptions and following certain rules: What am I doing? How am I doing it? and What am I going to do? Or What am I doing simultaneously?, so that you can pay attention to the maximum excitation/relevant stimulus.

\section{Focus}

This technique helps men to relearn how to think using all relevant sexual stimulus and how to manage the sensations that might rise sexual desire. In fact, this protocol stimulates men to think ",analytically” in order to achieve and maintain a firm erection which helps you control the erection.

\section{Specialist advice}

Are you familiar with a flight deck? If the answer is no, than ask the co-pilot! Substituting your attention on what you do rather than what you feel together with multitasking on several sexual stimulus, will help you to become an expert in sexual activity and to control your erection. This is what happens with an airplane pilot. Are you the pilot of the bed?

\section{Applications}

Make a description using internal monologue in order to cover step by step your partner's body by following these rules: What am I doing? How am I doing it? and What am I going to do? Or What am I doing simultaneously? and thus you can pay attention to what you feel.

Rule. You have the following exercises. First step, arousal (kisses), make a silent description of WHAT YOU DO (for instance, describe using internal monologue: "I start kissing the lips"). Then, carry on with the description, HOW YOU DO THAT (for instance, describe using internal monologue: "I kiss the lower lip, the upper lip, I touch her tongue and feel her tongue in my mouth"). Then, continue describing, WHAT YOU DO NEXT or WHAT YOU DO SIMULTANEOUSLY (for instance, describe using internal monologue: "I strat kissing down the neck and both sides of the neck while I am playing with one of her breasts").

Carry on in that way with the description for all stimulus/areas of your partner!

Follow the example from the Table 1.

\section{Well done!}

You have succeeded to complete the Protocol of sexual cognitive scenario S-ONde cognitive $\bigcirc$. I know that this was something new for you and I hope that you have learnt how to "analytically" think in order to manage the excitation stimulus and to have and to control your erection. 
Table 1. Description for all stimulus/areas of your partner

\begin{tabular}{|l|l|}
\hline FACE & $\begin{array}{l}\text { I start kissing the face, gently touching it with my lips, then I touch it, and then..., } \\
\text { etc., ... }\end{array}$ \\
\hline NECK & $\begin{array}{l}\text { I start kissing the neck, gently touching it with my lips, then I touch it, and then..., } \\
\text { etc., . }\end{array}$ \\
\hline BREASTS & $\begin{array}{l}\text { I start kissing the breasts, gently touching them with my lips, then I touch and } \\
\text { slowly pull them, rubb and pinch them, and then..., etc., ... }\end{array}$ \\
\hline ABDOMEN & $\begin{array}{l}\text { I start kissing the abdomen, gently touching it with my lips, then I touch it, rubb it, } \\
\text { slowly pinch it, and then..., etc., ... }\end{array}$ \\
\hline BACK & $\begin{array}{l}\text { I start kissing the back, gently touching it with my lips, then I touch it, rubb it, slowly } \\
\text { pinch it, then..., etc., ... }\end{array}$ \\
\hline ARMS & $\begin{array}{l}\text { I start kissing the arms, gently touching them with my lips, then I touch them, slowly } \\
\text { pull them, rubb and pinch them, and then..., etc., ... }\end{array}$ \\
\hline VAGINA & $\begin{array}{l}\text { I start kissing the vagina, gently touching it with my lips, slowly pull it, I insert my } \\
\text { finger into vagina, I rubb it and pinch the labia, etc., ... }\end{array}$ \\
\hline BUTTOCKS & $\begin{array}{l}\text { I start kissing the buttocks, gently touching them with my lips, then I touch them } \\
\text { and slowly pull them, rubb and pinch them, and then..., etc., ... }\end{array}$ \\
\hline LEGS & $\begin{array}{l}\text { I start kissing the legs, then I touch them and slowly, pull them, rubb and pinch } \\
\text { them, and then..., etc., ... }\end{array}$ \\
\hline
\end{tabular}

\section{Feedback}

Was the Protocol of sexual cognitive scenario S-ONde cognitive $@$ useful for you? Please express your content by crossing one of the statements bellow:

1. Unsatisfactory

2. Satisfactory

3. Good

4. Very good

5. Excellent

Funding Sources: This research did not receive any specific grant from funding agencies in the public, commercial, or not-for-profit sectors.

\section{RESOURCES}

1. Bakker D. \& Rickard N. (2018). Engagement in mobile phoneapp for self-monitoring of emotional well being predicts changes in mental health: MoodPrism. Elsevier Science.

2. BinDhim NF., Alanazi EM., Aljadhey H., Basyouni MH., Kowalski SR., Pont LG., Shaman AM., Trevena L., Alhawassi TM. (2013). Does a Mobile Phone Depression-Screening App Motivate Mobile Phone Users With High Depressive Symptoms to Seek a Health Care Professional's Help? J Med Internet Res. 2016 Jun; 18(6): e156.
3. Wiederhold K. B., \& Bouchard S. (2014). Advances in Virtual Reality and Anxiety Disorders. Springer.

4. Sharkey M. P. \&Merrick J.(2014). Virtual Reality: Rehabilitation in Motor, Cognitive and Sensorial Disorders. Nova SciencePub Inc.

5. Sandrini G. \& Homberg V. (2018). Advanced Technologies for theRehabilitation of Gaitand Balance Disorders. Springer.

6. Pons L. J., Raya R. \&González J. (2015). Emerging Therapies in Neurorehabilitation II (Biosystems\&Biorobotics). Springer.

7. Springer C. (1996). Electronic Eros: Bodies and Desire in the Postindustrial Age. FSU Bookshelf. 25.

8. https://www.appi.org/products/dsm-mobileapp

9. APA (2000). Diagnostic and Statistical Manual of Mental Disorders, 4th Edition, Text Revision (DSM-IV-TR). American Psychiatric Association.

10. APA (2013). Diagnostic and Statistical Manual of Mental Disorders, 5th Edition: DSM-5. American Psychiatric Association.

11. Frey K \&Hojjat M. (2010). Are love styles related to sexual styles? The Journal of Sex Research. Pages 265-271. Volume 35, 1998 - Issue 3.

12. Stephenson J. Imrie J. Chris Bonnell C. (2003). Effective Sexual Health Interventions: Issues in Experimental Evaluation. Oxford University Press. 
13. Fisher D. T. Davis M. C. Yarber L. W. Milhausen R. Sakaluk J. (2019). Handbook of Sexuality-Related Measures. 4th Edition. Routledge.

14. Copeland L. (2005). A Practitioner's Guide to Software Test Design. ArtechHouse.

15. Wincze P. J. Weisberg B. R. (2015). Sexual Dysfunction, Third Edition: A Guide for Assessment and Treatment. The Guilford Press; Third edition.
16. Weeks G. (2015). A Clinician's Guide to Systemic Sex Therapy. Routledge; 2 edition.

17. Hedges E. L. (2010). Sex in Psychotherapy: Sexuality, Passion, Love, and Desire in the Therapeutic Encounter. Routledge.

18. Rickard L. C. (2006). Creating Compliance: A Toolbox of Coping Skills HandoutsEActivities to Foster Treatment Compliance.Trafford Publishing. 